\title{
E Importance of Axial Migration of Spinal Cord Stimulation Trial Leads with Position
}

Chong H. Kim, MD', Adam W. Green, MD', Drew E. Rodgers, MD', Mohammed A. Issa, MD², and Monica A. Ata, MD ${ }^{1}$

From: ${ }^{1}$ West Virginia University, Morgantown, WV; and ${ }^{2}$ Brigham and Women's Hospital, Boston

MA

Address Correspondence: Chong $\mathrm{H}$. Kim, MD

Dept of Neurosurgery/ Pain Division

West Virginia University 1550 University Ave Morgantown, WV 26506 E-mail:

kimc@wvuhealthcare.com

Disclaimer: There was no external funding in the preparation of this manuscript. Conflict of interest: Each author certifies that he or she, or a member of his or her immediate

family, has no commercial association (i.e., consultancies, stock ownership, equity interest, patent/licensing arrangements, etc.) that might post a conflict of interest in connection with the submitted manuscript.

Manuscript received: 07-24-2013 Revised manuscript received: 06-02-2013:

Accepted for publication: 07-01-2013

Free full manuscript: www.painphysicianjournal.com
Background: Spinal cord stimulation (SCS) is an established treatment option for chronic pain. Prior to permanent implantation, temporary trials are performed to evaluate the SCS treatment. During the trial period, it is common for the patients to experience changes in paresthesias. However, it is unclear what the role of lead migration is, if any, in the changes in paresthesia.

Objective: To evaluate the role of lead migration on the effect of postural stimulation changes during SCS trials.

\section{Study Design: Case series.}

Setting: University pain management center.

Methods: X-rays of the patients with successful trials, in sitting and standing position, were obtained at the end of a 7 day SCS trial. Data were collected based on the need for adjustment of the stimulation settings due to changes in paresthesias with postural change of sitting versus standing.

Results: The average lead migration was $3.05 \mathrm{~mm}$ inferiorly from a standing to sitting position for all subjects. The average migration was $2.85 \mathrm{~mm}$ in subjects requiring adjustment of the SCS setting due to change in paresthesia compared to $3.24 \mathrm{~mm}$ for those who did not require adjustment regardless of position. The results were insignificant based on $P=0.17$.

Limitations: Small sample size, case series.

Conclusions: This case series demonstrates continued support for the role of the width of the cerebral spinal fluid space as the significant factor on paresthesia changes in SCS with respect to postural changes, even during the trial period.

Key words: Spinal cord stimulation, postural change, lead migration, paresthesia, neurostimulation, chronic pain, dorsal column

Pain Physician 2013; 16:E763-E768 pinal cord stimulation (SCS), by delivering electrical pulses to the spinal neural tissue to generate a paresthesia and thereby overlapping with the region of pain, has become an established treatment option for chronic intractable pain (18). Though there are a variety of methods, prior to permanent implantation, a trial is most commonly performed using percutaneous leads. Due to SCS trial's reversibility, minimal invasiveness, low complication rate, and effectiveness, a trial allows the patient and physician to assess the individual response and potential benefit $(9,10)$. During the trial, the patient is able to assess the stimulation as well as be evaluated for their willingness and compliance with 
the SCS treatment. The trial process also provides the opportunity to identify the precise location to best provide the appropriate stimulation. Unfortunately, there are limitations as well as the ultimate possibility of an unsuccessful SCS trial.

One common limitation is the change in the location and intensity of paresthesia due to postural position changes $(11,12)$. The change in paresthesia intensity is proposed to be due to changes in the distance between the lead in the epidural space and the dorsal column fibers $(13,14)$. For example, the paresthesia perception is commonly affected when the patient changes position such as from the standing to supine position. The pain coverage and comfort for standing might be too intense in the supine position, or inadequate when standing from a supine position (15). Another possibility is the change or loss of paresthesia. The coverage may be satisfactory when standing but lost when sitting, or vice versa. During the trial period, this may be due to migration of the lead within the epidural space, independently, and in addition to the distance changes from the doral column fibers.

The effect on location and intensity of paresthesia due to distance changes in respect to the doral column fibers has been well documented. However, during an SCS trial, the possible role of lead migration due to postural changes is unclear.

\section{Methods}

\section{Patients}

The patients were referred to the University Pain Management Center for evaluation and treatment of chronic pain. The patients were treated with successful SCS trials during a 6 month interval from 2009 to 2010. Twelve consecutive patients that experienced paresthesia changes and 12 consecutive patients that did not were included.

\section{Procedure}

The patients were all evaluated and the treatment option of SCS was offered. All 3 manufacturers' information, Boston Scientific (BS), Medtronic (MT), and St. Jude (SJ) was provided to all patients for review. All patients were screened and cleared by Pain Psychology and Psychiatry Services in the Department of Behavioral Health prior proceeding to the SCS trial. All patients underwent a 7-day SCS trial with one percutaneous 8 electrode lead performed by one staff member. The trial leads were sutured and steri-stripped in place.
At the end of the trial period, patients with successful trials were asked about changes in the location and/or intensity of paresthesia with position changes and the need for manual adjustment of the stimulation intensity or program. All of the patients underwent imaging in sitting and standing positions. Data were collect on 12 consecutive patients who described the need for adjustment and 12 patients who did not need adjustment from sitting to standing. Twenty-four total patients who elected to proceed to the permanent implantation with thoracic lead placement for pain in lower extremity were included.

\section{Data Collection}

The x-ray imaging of the patients in sitting and standing positions were examined. The lead placement and changes with position from standing to sitting were measured. The distance from the tip of the electrode in relation to the superior endplate was calculated and compared.

\section{Statistical Analysis}

Due to relative small number of patients, the averages were calculated and compared. T-test analysis was used for determination of significance. Less than 0.5 was considered significant.

\section{Results}

The average lead migration was $3.05 \mathrm{~mm}$ inferiorly from a standing to sitting position for all patients, with migration seen in every patient. Table 1 shows the lead movement in standing to sitting postural change. Table 2 shows the psoture related to stimulation change. The average migration was $2.85 \mathrm{~mm}$ in patients requiring adjustment of the SCS setting due to changes in paresthesias compared to $3.24 \mathrm{~mm}$ for those who did not require adjustment regardless of position. The results were insignificant based on T-test, $P=0.17$. The average age of the patients was 52.7 years, 55.6 years for men and 50.3 years of age for women. The average height of women that experienced stimulation changes from sitting to standing was 59 inches, compared to 64 inches in those that did not. In men, the height was 66 inches and 71 inches, respectively. Table 3 lists patient characteristics.

\section{Discussion}

This case series demonstrates continued support for the role of the width of the cerebral spinal fluid (CSF) space as the significant factor on paresthesia changes in 
Table 1. Lead movement in standing to sitting postural change.

\begin{tabular}{|l|c|c|c|c||}
\hline SCS company & Number of subjects & Movement in millimeters & Standard Deviation & Confidence Interval (.95) \\
\hline BS & 8 & 3.66 & 0.76 & 0.02 \\
\hline MT & 8 & 2.74 & 1.01 & 0.02 \\
\hline SJ & 8 & 2.74 & 0.93 & 0.02 \\
\hline Total Average & 24 & 3.05 & 0.97 & 0.01 \\
\hline
\end{tabular}

Table 2. Posture related stimulation change.

\begin{tabular}{|c|c|c|c|c||}
\hline \multirow{2}{*}{ Paresthesia change } & Number of subjects & Movement in millimeters & Standard Deviation & Confidence Interval (.95) \\
\hline Yes & 12 & 2.85 & 1.23 & 0.02 \\
\hline No & 12 & 3.24 & 0.61 & 0.01 \\
\hline
\end{tabular}

Table 3. Patient characteristics.

\begin{tabular}{|c|c|c|c|c|c|c|}
\hline Patient \# & Age & Sex & Diagnosis & SCS Company & Movement & Paresthesia Change \\
\hline 1 & 72 & $\bar{M}$ & PVD & $\overline{\mathrm{MT}}$ & 3.0 & $\mathrm{~N}$ \\
\hline 2 & 57 & $\mathrm{~F}$ & PLLS & MT & 2.0 & $\mathrm{~N}$ \\
\hline 3 & 45 & M & PLLS & BS & 3.0 & $\mathrm{~N}$ \\
\hline 4 & 49 & M & PLLS & BS & 3.0 & $\mathrm{Y}$ \\
\hline 5 & 55 & $\mathrm{~F}$ & PLLS & BS & 3.1 & $\mathrm{~N}$ \\
\hline 6 & 42 & $\mathrm{~F}$ & PLLS & BS & 4.5 & $\mathrm{Y}$ \\
\hline 7 & 37 & $\mathrm{~F}$ & PLLS & MT & 2.7 & $\mathrm{Y}$ \\
\hline 8 & 62 & $\mathrm{M}$ & PLLS & MT & 4.5 & $\mathrm{~N}$ \\
\hline 9 & 68 & $M$ & PLLS & SJ & 2.0 & $\bar{Y}$ \\
\hline 10 & 41 & M & PLLS & SJ & 4.0 & $\mathrm{Y}$ \\
\hline 11 & 52 & $\mathrm{~F}$ & CRPS & BS & 5.0 & $\bar{Y}$ \\
\hline 12 & 67 & $\mathrm{~F}$ & Neuropathy & BS & 3.5 & $\mathrm{~N}$ \\
\hline 13 & 32 & $\mathrm{~F}$ & PLLS & BS & 3.2 & $\mathrm{Y}$ \\
\hline 14 & 52 & $\mathrm{M}$ & PLLS & BS & 4.0 & $\mathrm{~N}$ \\
\hline 15 & 52 & $\mathrm{~F}$ & PLLS & SJ & 3.5 & $\mathrm{~N}$ \\
\hline 16 & 34 & $\mathrm{~F}$ & PLLS & SJ & 2.8 & $\mathrm{Y}$ \\
\hline 17 & 38 & $\mathrm{~F}$ & PLLS & SJ & 1.0 & $\mathrm{Y}$ \\
\hline 18 & 44 & $\mathrm{M}$ & Neuropathy & SJ & 5.1 & $\mathrm{~N}$ \\
\hline 19 & 48 & $\mathrm{~F}$ & PLLS & MT & 1.0 & $\mathrm{Y}$ \\
\hline 20 & 54 & M & PLLS & SJ & 3.5 & $\mathrm{~N}$ \\
\hline 21 & 82 & $\mathrm{~F}$ & PLLs & MT & 3.0 & $\mathrm{~N}$ \\
\hline 22 & 62 & M & PLLS & SJ & 2.5 & $\mathrm{Y}$ \\
\hline 23 & 58 & $\mathrm{~F}$ & PLLS & MT & 2.5 & $\mathrm{Y}$ \\
\hline 24 & 62 & M & PLLS & MT & 3.2 & $\mathrm{~N}$ \\
\hline
\end{tabular}

PVD - Peripheral vascular disease, PLLS - Post lumbar laminectomy syndrome, CRPS - Complex regional pain syndrome 
SCS use with respect to postural changes, even during the trial period $(16,17)$. Numerous studies have demonstrated that distances between the electrodes and the targeted spinal tissues change dramatically with body position (18-22). The spinal cord moves in an anteriorposterior position within the subarachnoid space during position changes. This space separating the 2 includes epidural vasculature, adipose tissue, dura matter, arachnoid membrane, CSF, and pia matter. It has also been shown that the CSF thickness is the most variable (18). The CSF also has the highest electrical conductivity while the epidural space surrounding the electrode has the lowest. Therefore, a lead that is positioned more posterior in the epidural space will have higher impedance and higher thresholds for paresthesias (22). Unfortunately we did not record the impedance with the postural changes. Additionally, the thickness of the CSF among individuals varies (23). Therefore, with an electrode in a fixed position within the epidural space, the anatomic and physiologic basis for variation in paresthesia is the distance between the SCS electrodes and the spinal cord as well as the thickness of the CFS (Fig. 1).

During a SCS trial with temporary leads, another variable is added. Since the electrode lead is anchored externally, the change in posture can result in migration and movement of the electrode within the epidural space. However, the results suggest that despite the inferior migration from a sitting position to a standing position, there is no correlation on the paresthesia experienced by the patients. Additionally, contrary to the expected, albeit statistically insignificant $(P=0.17)$, the average inferior migration was larger in those patients who did not require adjustment related to postural position change and therefore was not a predictor for paresthesia change ( $3.05 \mathrm{~mm}$ vs $2.85 \mathrm{~mm}$ ). More women noted paresthesia changes. The average height of these women was 59 inches compared to 64 inches in those that did not. However, the migration was less, 2.84 $\mathrm{mm}$ vs 3.02. Furthermore, the percentage of change, in regards to migration compared to the height, was the same $(0.05 \%)$. Finally, variations existed among various manufacturers in migration without any correlation or significance to paresthesia change. Lead migration inferiorly was the largest in BS (3.66 mm) leads compared to MT and SJ $(2.74 \mathrm{~mm})$.

The role of the trial period has long been studied and supported for optimization of SCS as a successful treatment for chronic pain. Various factors are associated with a successful trial (24). Conversely, minimizing

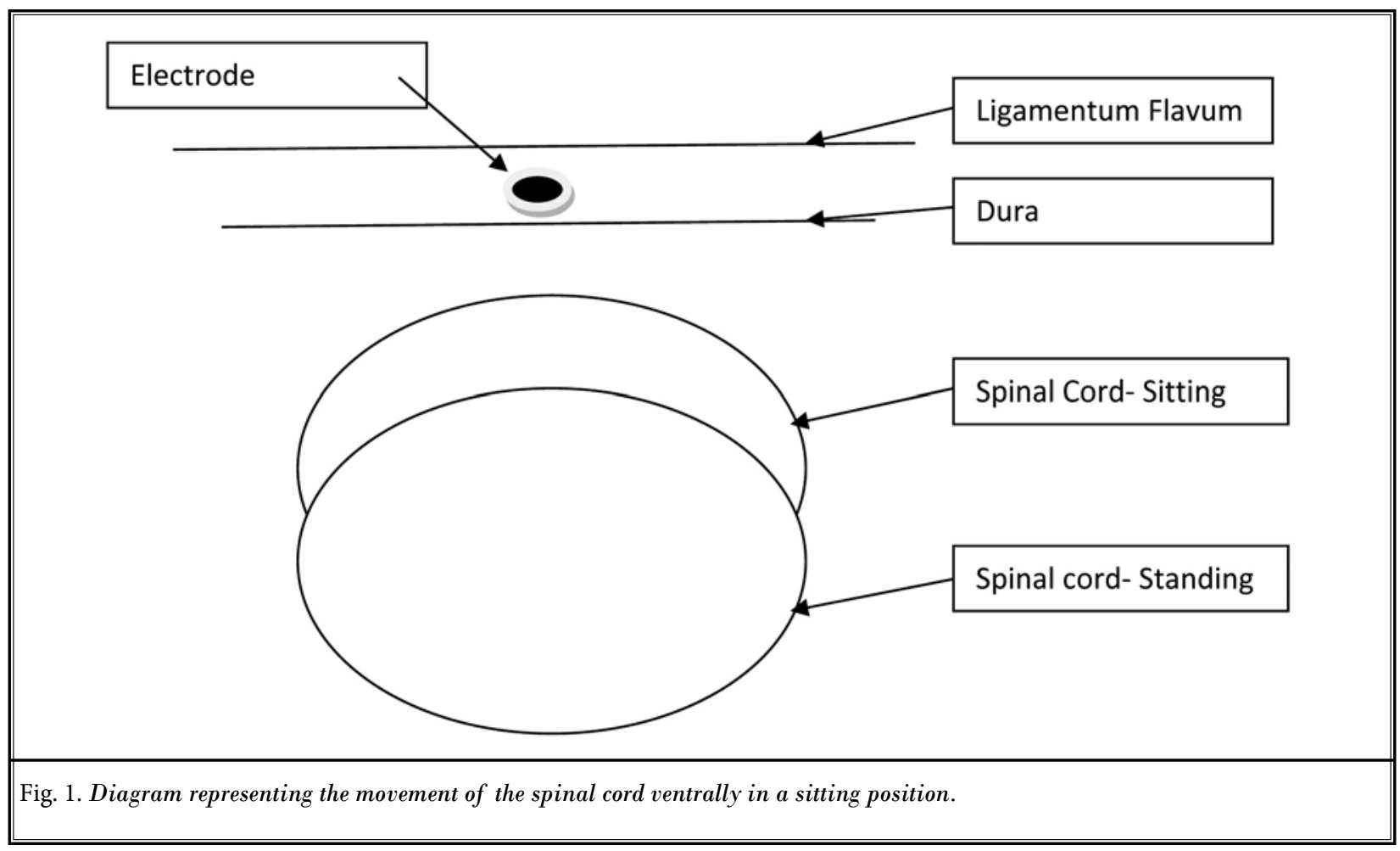


negative factors such as posture-related stimulation changes would likely improve the outcome. Currently, patients are provided tailored programming to improve the experience, such as specific configurations for walking or sleeping to optimize patient experience while minimizing parethesia changes. Paresthesia thresholds have been found to be higher in the sitting and standing positions when compared to the supine position. However, it was not significantly different in sitting and standing (12). In this report however, a significant number of patients noted the need for adjustment from a standing to sitting postural change. During the 6 month period, a total of 31 patients underwent an SCS trial, with 29 proceeding to a permanent implantation. Of the 29 patients, $17(58 \%)$ noted the need for stimulation adjustment due to significant paresthesia changes from a standing to sitting postural change. Surprisingly, this is less than the reported $71 \%$ in permanently implanted patients, although this study included changes from a supine position (25).

Recently, position-adaptive SCS has been introduced for permanent implantation to address stimulation changes related to patient position $(26,27)$. Even if the technology was available for the trial period, one concern is the lack of fixation of the electrode leads within the epidural space. Since 3 to 8 weeks are believed to be needed for the encapsulation of the epidural electrodes, even in permanently implanted patients, there is a delay post-operatively until the technology is utilized due to the need for encapsulation and stabilization of the electrode leads within the epidural space $(27,28)$. Based on the results, although the electrode leads are only fixed externally during the SCS trial, position-adaptive SCS may offer patients an improved trial experience or may be considered sooner following permanent implantation.

\section{Limitations}

Based on the sample size, case series design, and subjective nature of perceived stimulation, this study has limitations. Additionally, only patients that proceeded to permanent implantation were studied, limiting the data collection.

\section{Conclusions}

This study demonstrates inferior axial migration of percutaneously placed SCS leads with sitting from a standing position. Although the lead migrates inferiorly with sitting, there is no correlation of the inferior lead migration to changes in percieved paresthesias. Even during the trial SCS period, this case series provides support for the role of the width of the CFS space as the significant factor on paresthesia changes in SCS with respect to postural change.

\section{References}

1. North RB, Kidd DH, Zahurak M, James CS, Long DM. Spinal cord stimulation for chronic, intractable pain: Experience over two decades. Neurosurgery 1993; 32:384-394; discussion 394-385.

2. Barolat G, Massaro F, He J, Zeme S, Ketcik B. Mapping of sensory responses to epidural stimulation of the intraspinal neural structures in man.] Neurosurgery 1993; 78:233-239.

3. Barolat G, Zeme S, Ketcik B. Multifactoral analysis of epidural spinal cord stimulation. Stereotactic Funct Neurosurgery 1991; 56:77-103.

4. Holsheimer J. Effectiveness of spinal cord stimulation in the management of chronic pain: Analysis of technical drawbacks and solutions. Neurosurgery 1997; 40:990-996; discussions 996-999.

5. Long DM, Erickson D, Campbell J, North R. Electrical stimulation of the spinal cord and peripheral nerves for pain control. A 10-year experience. Appl
Neurophysiol 1981; 44:207-217.

6. Shealy CN, Mortimer JT, Reswick JB. Electrical inhibition of pain by stimulation of the dorsal columns: Preliminary clinical report. Anesth Analg 1967; 46:489-491.

7. Kumar K, Hunter G, Demeria D. Spinal cord stimulation in treatment of chronic benign pain: Challenges in treatment planning and present status, a 22-year experience. Neurosurgery 2006; 58:481496; discussion 481-496.

8. Tiede JM, Ghazi SM, Lamer TJ, Obray $J B$. The use of spinal cord stimulation in refractory abdominal visceral pain: Case reports and literature review. Pain Pract 2006; 6:197-202.

9. North RB. Spinal cord stimulation trial duration. Neuromodulation 2003; 6:4-5.

10. Kumar K, Wilson JR. Factors affecting spinal cord stimulation outcome in chronic benign pain with suggestions to improve success rate. Acta Neurochir
Suppl 2007; 97:91-99.

11. Cameron T, Alo KM. Effects of posture on stimulation parameters in spinal cord stimulation. Neuromodulation 1998; 1:177-183.

12. Olin JC, Kidd DH, North RB. Postural changes in spinal cord stimulation perceptual thresholds. Neuromodulation 1998; 1:171-175.

13. Dijkstra EA, Holsheimer J, Olthuis W, Bergveld P. Ultrasonic distance detection for a closed-loop spinal cord stimulation system. Proc 19th Ann Int Conf IEEE Eng in Med ex Biol Soc 1997; 5:1954-1957.

14. Holsheimer J, den Boer JA, Rozeboom. AR assessment of the normal position of the spinal cord in the spinal canal. Am J Neuroradiol 1994; 15:951-959.

15. Holsheimer J, Khan YN, Raza SS, Khan EA. Effects of electrode position on perception threshold and paresthesia coverage in spinal cord stimulation. Neuro- 
modulation 2007; 10:34-41.

16. Barolat G. Spinal cord stimulation for persisiten pain. In: Gilenberg $T$ and Tasker R (eds). Textbook of Stereotactic and Functional Neurosurgery. McGraw Hill, New York, 1997, pp. 1519-1537.

17. Barolat G. Epidural spinal cord stimulation: Anatomical and electrical properties of the intraspinal structures relevant to spinal cord stimulation and clinical correlations. Neuromodulation 1998; 2:63-71.

18. Holsheimer J, Struijk JJ. How do geometric factors influence epidural spinal cord stimulation? Sterotact Funct Neurosurg 1991; 56:234-239.

19. Struijk JJ, Holsheimer J, van der Heide GG, Boom HBK. Recruitment of dorsal column fibers in spinal cord stimulation: Influence of collateral branching. IEEE Trans Biomed Eng 1992; 39:903-912.

20. Struijk JJ, Holsheimer J, Boom HBK. Ex- citation of dorsal root fibers in spinal cord stimulation: A theoretical study. IEEE Trans Biomed Eng 1993; 40:632-639.

21. Struijk JJ, Holsheimer J, Barolat G, He J, Boom HBK. Paresthesia thresholds in spinal cord stimulation: A comparison of theoretical results with clinical data. IEEE Trans Rehabil Eng 1993; I:101-108.

22. He J, Barolat G, Holsheimer J, Struijk JJ. Perception threshold and electrode position in spinal cord stimulation. Pain 1994; 59:55-63.

23. Abejon D, Feler C. Is impedance a parameter to be taken into account in spinal cord stimulation? Pain Physician 2007; 10:533-540.

24. Chincholar $M$, Eldabe $S$, Strachan $R$ Brookes M, Garner F, Chadwick R, Gulve A, Ness J. Prospective analysis of the trial period for spinal cord stimulation treatment for chronic pain. Neuromodulation 2011; 14:523-529.
25. Ross E, Abejon D. Improving patient experience with spinal cord stimulation: Implications of position-related changes in neurostimulation. Neuromodulation 2011; 10:1525-1403.

26. Schade CM, Schultz D, Tamayo N, lyer $S$, Panken E. Automatic adaptation of neurostimulation therapy in response to changes in patient position: Results of the posture responsive spinal cord stimulation (PRS) research study. Pain Physician 2011; 14:407-417.

27. Schultz DM, Webster L, Kosek P, Dar $U$, Tan Y, Sun M. Sensor-driven position-adaptive spinal cord stimulation for chronic pain. Pain Physician 2012; 15:1-12.

28. Alo K, Varga C, Krames E et al. Factors affecting impedance of percutaneous leads in spinal cord stimulation. Neuromodulation 2006; 9:128-135. 